International Journal of Linguistics, Literature and Translation (IJLLT)

ISSN: 2617-0299 (Online); ISSN: 2708-0099 (Print)

DOI: $10.32996 / \mathrm{jjllt}$

Journal Homepage: www.al-kindipublisher.com/index.php/ijllt

\title{
The Impact of Students' Proficiency in English on Science Courses in a Foundation Year \\ Program
}

Mohammed Siddique Kadwa ${ }^{1 *}$ and Hamza Alshenqeeti ${ }^{2}$

${ }^{1}$ Language Specialist, Taibah University, Saudi Arabia

${ }^{2}$ Associate Professor, Taibah University, Saudi Arabia

Corresponding Author: Mohammed Siddique Kadwa, E-mail: dr.m.s.kadwa@gmail.com

\section{ARTICLE INFORMATION ABSTRACT}

Received: October 12, 2020

Accepted: November 30, 2020

Volume: 3

Issue: 11

DOI: 10.32996/ijllt.2020.3.11.5

\section{KEYWORDS}

CEFR, English, foundation year

program, placement test,

proficiency
English plays a crucial role in determining a student's academic success and career path in Saudi Arabia. This is one of the reasons why Saudi universities offer mandatory foundation year programs to university entrants. The assumption is that if a student has high proficiency levels in the English language, the student will be able to meet the challenges and demands of other science courses that are taught in the English language in the first-year program as well as the subsequent bachelor's programs. In order to prepare students for academic success, the tendency at most Saudi universities is to use international, mostly US or UK, publishers to provide the resources for its curriculum which is based on the Common European Framework of Reference for Languages (CEFR) as a standard for designating language ability. This study investigates the relationship between university students' English language levels and their performance in science courses in a foundation year program at a Saudi university. Using Oxford University's Q: Skills Placement Test, quantitative data is used to establish the students' language levels according to the internationally accepted CEFR scales. The scores were then correlated with students' overall averages in the science courses. Data was gathered over a period of five academic years and statistical analyses were conducted using Pearson's Correlation Coefficient formula and scatter plots. The findings and conclusions have fundamental implications for curriculum designers at universities in Saudi Arabia as well as institutions of higher education in the Middle East and the Arab world.

\section{Introduction}

The role of English at universities in Saudi Arabia is a multifaceted phenomenon. On the one hand, learners have to change from Arabic as the language of learning and teaching in Saudi Arabian high schools to English at universities where it is widely adopted as a medium of instruction. This creates several linguistic and literacy obstacles for Arabic first language (L1) learners. Therefore, a foundation year of studies was formulated to prepare school leavers for academic studies in English. On the other hand, partial testing techniques at high-schools means that the learners' English-language abilities cannot be established with certainty (Siddiek, 2011). Moreover, research suggests that the curricula are incomprehensively designed, which is why teaching practices are ineffective and students' English language competencies are thwarted. Therefore, there is a genuine need for university programs to modify their curricula through evidence-based research.

\section{Literature Review}

Much of second language acquisition research is based on the categorization of world Englishes as advocated by Kachru (1985, 1986a, 1987). The issue with Kachru's circles of world Englishes, however, is that it is too simplistic. The word foreign is applied to all countries where English is not used as an official language creating the assumption that they are equal and what works in one context will work in another. This is not the case though. For example, Germany and Saudi Arabia are both categorized as countries within the expanding circle, but one may argue that it would be swifter for German adults to learn

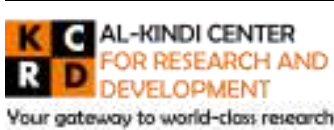

Published by Al-KindiCenter for Research and Development. Copyright (c) the author(s). This is an open access article under CC BY license (https://creativecommons.org/licenses/by/4.0/) 
English than Saudi adults. They differ drastically in terms of pragmatics, culture, orthography, textual norms, literary mechanisms, and linguistic genetics. However, the German language shares more of these commonalities with English than Arabic does. Therefore, it will be naïve to categorize German learners of English as having the same learning needs of Arabicspeaking students. Moreover, from a sociolinguistics perspective, the debilitating impact of contextual factors is ignored in the design of the curricula. For example, in a recent study that advocates against the use of a World Englishes view, contemporary English language teaching materials and approaches were found to represent Anglo-American cultural and linguistic standards and values while missing the complex essence of English today (Alshammari, 2015). Therefore, we argue that the oversimplified notion of classifying all languages where English is not used as an official language as one can be blamed for ineffective curriculums, teaching practices, and ultimately lacking English language competencies.

One of the reasons for the low standard of English in Arabic-speaking countries is that the Arabic language is not properly understood from an English language teaching standpoint. However, through comparative linguistics, it can be deduced that the Arabic language is very distant to the English language. Alasmari, Watson, \& Atwell (2016) point out that this is not recognized in research as it ought to. The authors highlight the fact that the Arabic verb system is more complex than what it is currently made out to appear. By comparing words on Google translate, they were able to prove that word to word translations are not accurate when translating Arabic sentences into English. Alasmari, Watson, \& Atwell's (2016) study exposes the notion that the Arabic language is not afforded much research attention by the English teaching fraternity as it is understudied. Furthermore, it shows that what research exists, is rarely applied to other linguistic contexts like translation studies and second language acquisition studies. This lack of proper recognition of the Arabic language in second language acquisition research has led to ineffective English language curriculums being designed for Arabic speakers and make the target language more challenging for Arabic learners.

The state of English in general has been a common theme among evaluative studies of English in Saudi Arabia. For example, Alfahadi (2012) and Alresheed (2012) attribute the sub-standard levels of English to perspectives held by students and challenges faced by teachers. In another study, Mahib ur Rahman \& AlHalsoni (2013) focus on learners and identifies the five main reasons behind Arabic-speaking learners' low command of the English language as a result of teaching practices, teaching curricula, insufficient exposure to the English language, and demotivation. Additionally, Al Khairy (2013) considers peer pressure and course difficulty as major contributors to demotivated undergraduates at Saudi universities in their foundation year.

Recent studies carried out in Saudi Arabia have a recurrent theme calling for change. For instance, Alebeikan \& Troudi (2010) investigated the implementation of blended learning at universities and concluded that universities face severe challenges when it comes to curriculum change. In another study by Khan (2011), that looked into teacher and student motivation, it was found that university courses had inappropriate target curriculums and barriers to learning were not taken seriously. The study further calls for proper diagnoses of learning barriers and changes to the design of curriculums. In a more recent study aimed at the preservation and protection of the Saudi Arabian educational context, it was found that curriculums were not sustainable (Alshuweikhat et al., 2016). Moreover, the researchers call for the adoption of sustainable approaches to university operations by enhancing research from a Saudi Arabian standpoint. This theme also reverberates in a qualitative study that advocates for change in the curriculums of Saudi Arabian universities whereby Yusuf (2017) identified ineffective curriculums as the chief obstacles towards achieving the demands of Saudi Arabia's Vision 2030 at universities. In addition, the research suggests that Saudi Arabian universities improve their scholarship in the area of sustainable operations within a Saudi Arabian framework using Vision 2030 as a starting point.

One of the major obstacles to proper curriculum design for Arabic learners is the Common European Framework of Reference (CEFR). It is the product of the European Nations (EU) and serves as a referent by many international English organizations. But this was not its original purpose. It was initially formulated to unite the EU's 14 European languages by establishing "a common basis for the elaboration of language syllabuses, curriculum guidelines, examinations, textbooks, etc." (CEF, 2001: 1). What English language curriculum designers in Arabic settings fail to acknowledge is that the CEFR was not designed for Arabic learners. This is the main reason why Arabic L1 learners require more than the stipulated learning time of 80 to 100 hours to master the beginner A1 level on the CEFR scales.

Concerning inadequate or incorrectly constructed curricula, Leung and Lewkowicz (2006) claim that there is not much work being conducted on credibility checking and the definition of legitimacy. In debating the ethics of testing, Leung and Lewkowicz (2006) cite Lynch (1997) who questions whether it is morally acceptable to have a person involved in an action that he or she simply cannot perceive as being specifically linked to the skill supposedly being tested? This line of questioning 
can be taken further by asking whether it is acceptable for language tests to place students at certain levels and not recognize this in the program of instruction. This was also questioned by (Author) and Sheik (2020) who found that although the CEFR based placement test was valid, it was unable to accurately discriminate between low level students. Moreover, it was found that the CEFR based curriculum was unable to provide the resources or direction for instruction to meet the linguistic needs of low-level students.

Although no studies were conducted in Saudi Arabia to expose the correlation and impact of the English language on other academic courses, recent studies in other foreign language settings provide valuable insight. For example, Kamrul Hasan and Akhand (2014) concluded that the English language was a good predictor of academic success for undergraduate purposes. In a Nigerian context too, Fakeye and Ogunsiji (2009) found that high school students' English proficiency levels portray a significant positive relationship with overall academic success. Moreover, the researchers recommended that attempts to improve academic success should be directed towards the strengthening of the English language curriculum. However, in the UAE, Dev and Qiqieh (2016) found contradictory results. The researchers compared data from both native and non-native speakers of English and found that students' performance on the IELTS test was found to have no direct impact on academic achievement. Furthermore, in a Somalian context, Addow, Abubakar and Abukar (2013) concluded that although the English language levels of Somali university students demonstrate a positive relationship with academic success, students' general study skills were a better indicator of academic success in higher education. This finding coincides with Khajavy, Maclntyre, and Hariri's (2020) assertion that in an Iranian context, the intrinsic cognitive factors of grit and perseverance are better predictors of academic success than students' language mindset. The above-mentioned studies expose the fact that context plays an important role in determining whether the impact of English on academic success is significant or not. Moreover, any decisions based on the predictive nature of English competencies on other courses have to acknowledge students' perseverance and general study skills.

The literature evidenced in this section exposes some serious flaws in English language curricula designed for Middle Eastern contexts. Moreover, previous studies that investigated the impact of English on academic success showed varied findings depending on the context. However, none of them were conducted from a curriculum design or CEFR perspective. The growing discontent by researchers with the current CEFR based syllabi was also brought to the fore. Moreover, the demands of Saudi Arabia's Vision 2030 call for a complete overhaul of English language practices by the Saudization of all aspects of the English curriculum by taking into account the difficulties faced by Arabic learners.

\section{Theoretical Framework}

This study is guided by the principles of the positivistic paradigm, which is also referred to as normative and is objective in nature. The positivistic school of thought's main thinkers includes philosophers such as Aristotle, Descartes, and Galileo (Mack, 2010). It is most notable for its ability to relate the social sciences with the natural sciences by applying the same scientific rigor (Cohen Manion and Morrison, 2007). Furthermore, it is data-driven and relies heavily on statistics. It seeks rules and generalizations by deconstructing phenomena to its basic components. Axiologically, it is etic. Research is conducted in a value-free manner whereby the researchers view the data from the outside. The researchers maintain objectivity and is independent of the phenomena under study. In terms of research methodology, positivists mostly employ quantitative methods to gather data (Wahyuni, 2012). The positivist paradigm is often criticized for its application of the scientific approaches of natural science research to the human and social science (Mack, 2010). Its critics argue that positivist researchers' obsession with numerical or statistical data reduces the complexities of human phenomena to mere digits, figures, and numbers. To counteract this criticism, a description of the foundation year program will be elucidated to paint a picture of the setting within which the findings are made.

\section{Research Questions}

1. How is the curriculum of the foundation year program at a Saudi Arabian university structured?

2. What are the language levels of Saudi Arabian university students in a foundation year program?

3. Is there a relationship between English language proficiency levels and performance on other courses in the foundation year program?

\section{Method}

In order to achieve its aims, three things need to be established. Firstly, a description of the structure of the foundation year program has to be provided. Secondly, the students' English language levels have to be ascertained prior to the academic 
year and correlated against a similar test at the end of the program to establish its validity. Thirdly, the students' scores have to be correlated against their overall foundation year program averages.

This study uses data collated over a five-year period. In total, 42,378 students' scores were used. However, it has to be noted that each student's scores were obtained twice; once each semester. The subjects were foundation year students at a Saudi Arabian university. A point to note is that although education in Saudi Arabia is gender-segregated, this research is not gender-biased as the scores of both male and female students were used to establish whether the English language competencies impact other courses. Also, the Q: Skills Placement Test that was used in this study was the same for all the students throughout the study.

In terms of data analyses, this study interrogates the data through both statistical and graphical techniques to ascertain relationships, if any. The correlations are computed using Pearson's correlation coefficient formula. Statistically, once computed, a positive correlation would exist if the two variables approximate +1 . Consequently, there would be no relationship between the two variables as the correlated coefficient nears zero (0). The results are complemented by scatter plots which graphically illustrate the extent of the relationships.

\section{Limitations}

Although this study is conducted from a quantitative perspective, in terms of generalizability, its findings cannot be readily applied to different settings without acknowledging the context of the study. The results would mostly be beneficial to foundation year programs in Saudi Arabia more than other locations. Another limitation of this study is that it does not recognize and expose the various interventions and changes in curricula and pedagogy throughout the five-year period within which this study was conducted. Lastly, a very small proportion of overall student scores have been inflated as students were either condoned or awarded scores based on different assessment methods as a consequence of being absent on examination dates.

\section{Findings}

The findings are categorized below in the order in which the research questions were posed earlier.

\subsection{Description of the Foundation Year Program}

The foundation year program at the university wherein this study takes place is structured into two plans which are offered in both the semesters. Plan A includes introductory courses in biology, physics, computer skills, university life skills, and English language skills. Plan B, on the other hand, includes Islamic studies, Arabic, introductory courses to mathematics and chemistry, as well as English language skills. It is worthwhile to point out that acceptance in the English course of the second semester is dependent on its prerequisite English course of the first semester. Moreover, the language of instruction, including textbooks and tests are in English for all the subjects accept Arabic and Islamic studies which are delivered in Arabic. Students' cumulative performance scores are then used to determine whether they are eligible for bachelor programs in the medical, engineering, humanities, and commerce colleges.

In the analysis of the data, it will be interesting to note whether students' order of subjects according to their study plans have any significant impact on their overall grades. Another important factor to note is that the English language courses as well as the Q-Skills Placement Test in the foundation-year program are CEFR aligned. Both have been designed and published by Oxford University and its benchmarking and correlation to other tests can be seen in the table below.

Table 1: Oxford Q-Skills Placement Test Conversion Chart

\begin{tabular}{|c|c|c|c|c|c|}
\hline $\begin{array}{l}\text { Q: Skills Placement } \\
\text { Level }\end{array}$ & Scores (\%) & $\begin{array}{l}\text { TOEFL } \\
\text { (Paper) }\end{array}$ & $\begin{array}{l}\text { TOEFL } \\
\text { (iBT) }\end{array}$ & IELTS & CEFR Levels \\
\hline Level 0 & $0-10$ & $0-343$ & $0-18$ & $1-1.5$ & \multirow[t]{2}{*}{ A1 (Breakthrough) } \\
\hline Level 1 & $11-30$ & $347-393$ & $19-29$ & $2-2.5$ & \\
\hline Level 2 & $31-50$ & $397-435$ & $30-40$ & $3-3.5$ & A2 (Waypoint) \\
\hline Level 3 & $51-70$ & $437-473$ & $41-57$ & $4-4.5$ & B1 (Threshold) \\
\hline Level 4 & $71-90$ & $513-547$ & $58-74$ & $5-5.5$ & B2 (Vantage) \\
\hline Level 5 & $91-100$ & $550-587$ & $75-90$ & $6-7$ & $\begin{array}{l}\text { C1 (Effective Operational } \\
\text { proficiency) }\end{array}$ \\
\hline
\end{tabular}

Adapted from: http://www.relod.ru/files/files/tablitsa_urovnei_242.pdf 
The publishers, Oxford University Press, claim that the Q: Skills Placement Test is on par with other internationally renowned tests such as the TOEFL and IELTS. However, there are two noticeable differences according to the conversion chart above. Firstly, the Q: Skills Placement Test divides the A1 level into Level 0 and Level 1 . The rationale behind this division, however, is unknown. As such, this study will treat all scores under 30 as that of the A1 level. The other observation is that the Q: Skills Placement Test does not recognize the $\mathrm{C} 2$ level of the CEFR.

The aim of the foundation-year English program is to take students up to the B1 level. As such, students begin with the ENG101 course which begins at the A1 level and stops midway of the A2 level in the first semester. Upon successful completion of ENG101, students' progress into ENG102 in the second semester, which begins at the middle of the A2 level and finishes at the end of the B1 level.

\subsection{Determining students' English Language levels}

During the first week of each academic year, students' English language levels were established using the Oxford Q-Skills Placement Test. From a content validity standpoint, it is appropriate as the Oxford series is being used for the teaching of English courses in the first-year program. The table below shows the results of the placement tests according to the CEFR levels by using the conversion chart in table 1 above.

Table 2: Placement Test Results according to CEFR Levels and Gender

\begin{tabular}{|c|c|c|c|c|c|c|c|c|}
\hline \multirow[b]{2}{*}{ Year } & \multirow[b]{2}{*}{ Gender } & \multicolumn{5}{|c|}{ CEFR LEVELS } & \multirow[b]{2}{*}{ Sub } & \multirow[b]{2}{*}{ TOTAL } \\
\hline & & A1 & A2 & B1 & B2 & C1 & & \\
\hline \multirow{2}{*}{ 2014-2015 } & $M$ & 131 & 929 & 204 & 76 & 1 & 1341 & \multirow{2}{*}{2501} \\
\hline & $\mathrm{F}$ & 74 & 822 & 196 & 68 & 0 & 1160 & \\
\hline \multirow{2}{*}{$2015-2016$} & $M$ & 8 & 159 & 142 & 177 & 10 & 496 & \multirow{2}{*}{884} \\
\hline & $\mathrm{F}$ & 5 & 98 & 149 & 130 & 6 & 388 & \\
\hline \multirow{2}{*}{ 2016-2017 } & $M$ & 171 & 1102 & 231 & 114 & 1 & 1619 & \multirow{2}{*}{2605} \\
\hline & $\mathrm{F}$ & 53 & 681 & 180 & 69 & 3 & 986 & \\
\hline \multirow{2}{*}{$2017-2018$} & $M$ & 238 & 1193 & 258 & 112 & 6 & 1807 & \multirow{2}{*}{2912} \\
\hline & $\mathrm{F}$ & 82 & 741 & 179 & 83 & 20 & 1105 & \\
\hline \multirow{2}{*}{ 2018-2019 } & $M$ & 208 & 1005 & 231 & 161 & 18 & 1623 & \multirow{2}{*}{2439} \\
\hline & $\mathrm{F}$ & 50 & 460 & 173 & 114 & 19 & 816 & \\
\hline & & 1020 & 7190 & 1943 & 1104 & 84 & 11341 & 11341 \\
\hline & & $8,99 \%$ & $63,39 \%$ & $17,13 \%$ & $9,73 \%$ & $0,07 \%$ & & \\
\hline
\end{tabular}

According to the data in the table above, the majority (63\%) of students are at the A2 level upon entry to the foundation year program. Although a sizeable proportion of students (17\%) are at the B1 level, even smaller proportions of students are at the B2 and C1 levels respectively. What is worrisome though, is that a significant percentage (9\%) of students are at the A1 level. Considering the amount of money and effort invested by the Saudi Arabian authorities in English language education in the primary, intermediate, and secondary schooling phases, this predicament is in urgent need of redress. From a probability standpoint, the data above indicates a normal distribution of scores where most of the observed scores cluster around a central peak and taper away from the summit relatively equally in both directions. Another important observation gleaned from the data is that there are no significant differences in the English language levels according to gender.

As a validation exercise, the students' English language scores were validated via the test-retest method. As such, the same test which was administered to students as a pre-course test was later re-administered to the students' as a post-course test. The data was then computed to determine whether progress was made, as well as to establish whether a positive correlation exists between the pre-course test and the post-course English test. These results of the correlation using Pearson's correlation coefficient formula are presented in the table below. 
Table 3: Table of Correlations between the English Language Pre-Course and Post-Course Tests

\begin{tabular}{|c|c|c|}
\hline YEAR & Number of Students & Correlations \\
\hline $2014-2015$ & 1557 & 0.930 \\
\hline $2015-2016$ & 1444 & 0.691 \\
\hline $2016-2017$ & 1499 & 0.695 \\
\hline $2017-2018$ & 1149 & 0.537 \\
\hline $2018-2019$ & 1101 & 0.524 \\
\hline
\end{tabular}

In terms of understanding Pearson's formula, the closer the output approximates one, the stronger the relationship between the two variables. Moreover, positive numbers indicate a positive correlation whilst negative integers indicate a negative relationship exists between the two tests. According to Table 3, the correlation between the pre-course test and the postcourse test was much stronger in 2014-2015 than in the subsequent years. An explanation of this anomaly is that during the academic year 2014-2015, students were awarded up to 3 bonus marks for obtaining higher scores on the post-course test. However, this policy was abandoned in the subsequent years leading to a dramatic decrease in the correlation of the two tests. The data is also graphically illustrated in scatter plots below to provide visual indications of the strength of the relationships.

Table 4: Scatter Plots Showing Correlations between the English Pre-Course and Post-Course Tests

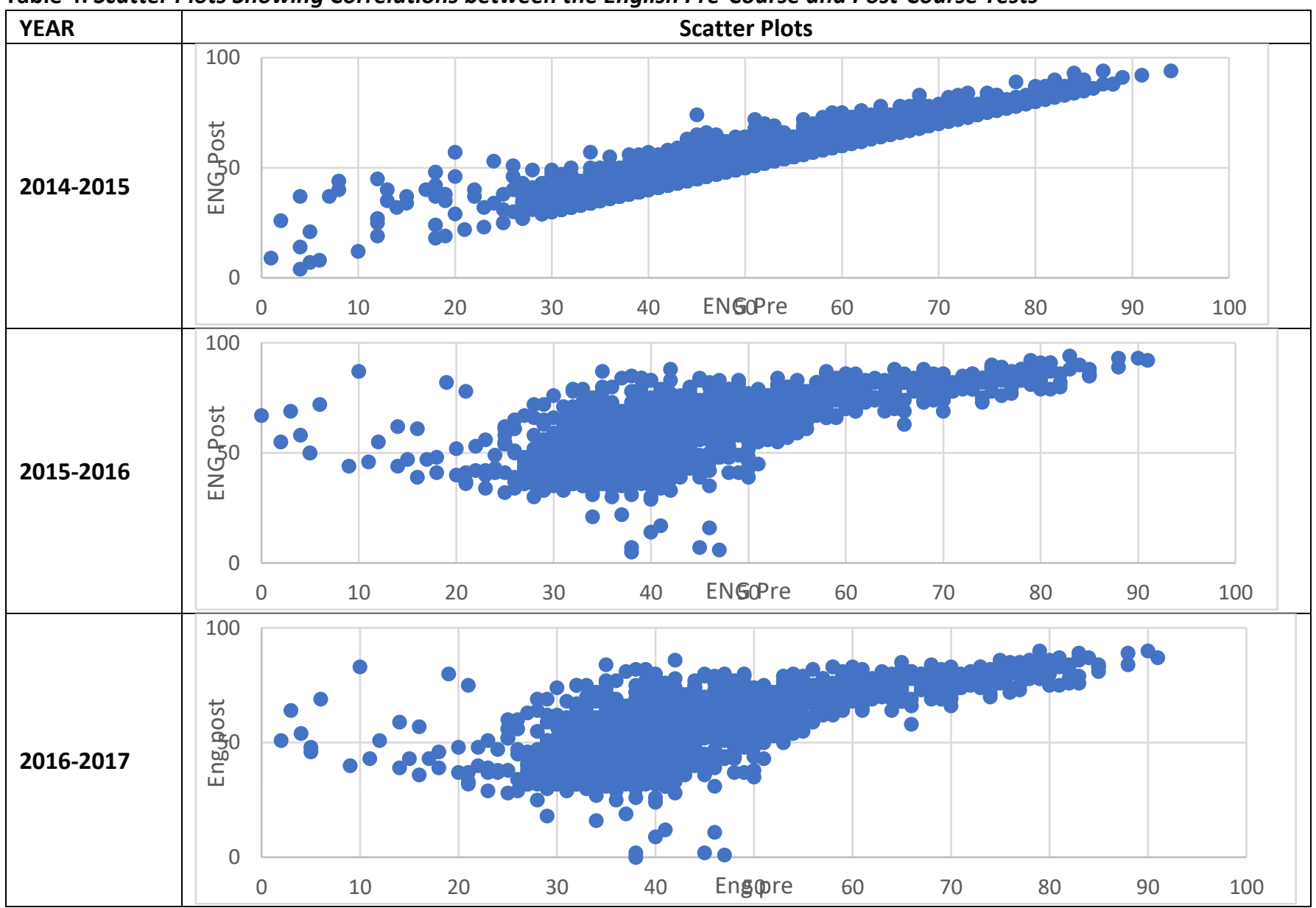




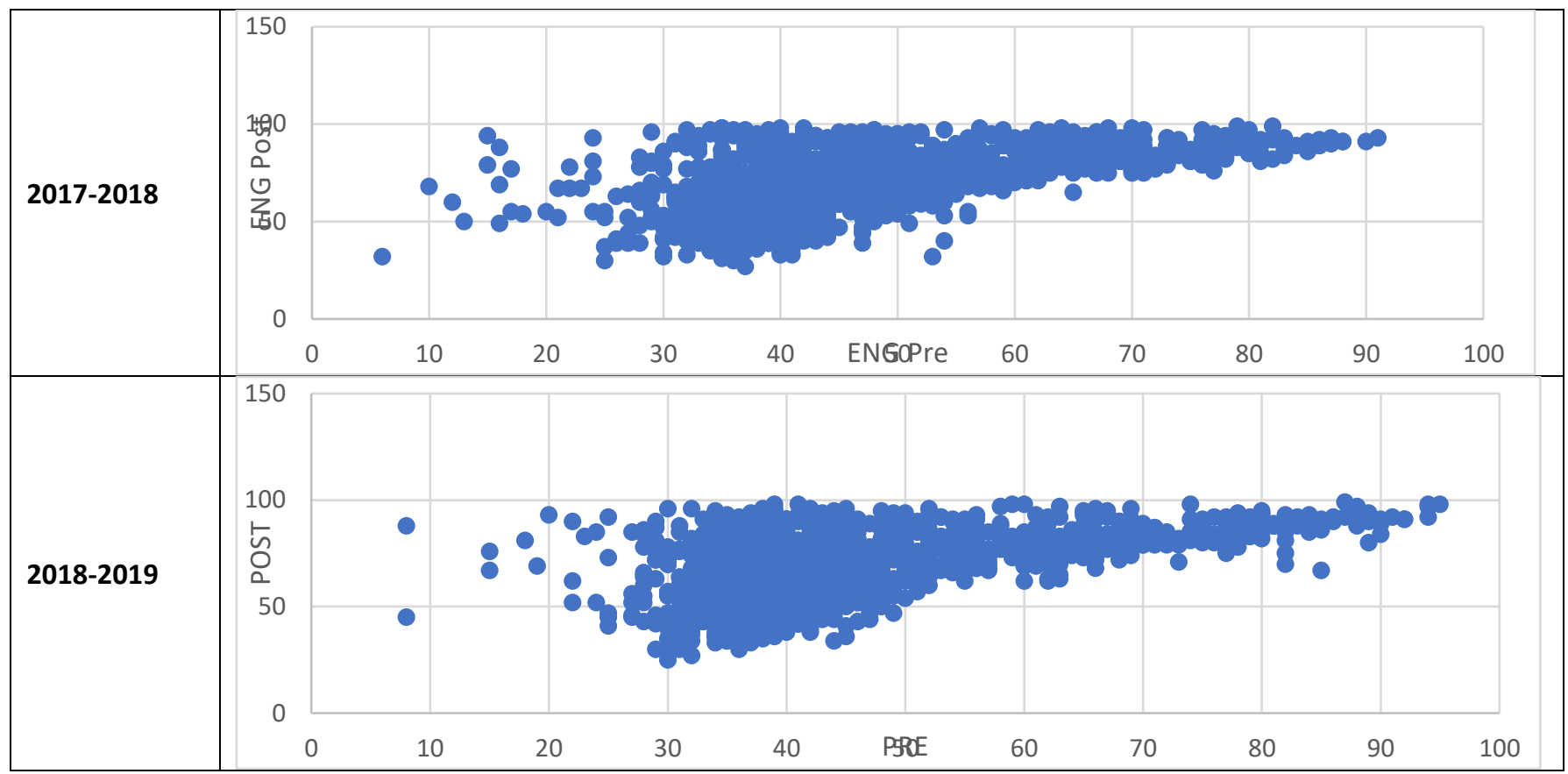

In comparing the data between the pre-course and post-course tests of English language skills, the scatter plots indicate that a positive relationship exists between the two tests. The horizontal axes show the results of the pre-course tests, whilst the vertical axes show the results of the post-course tests. As such, the data represented on the scatter plots show fairly straight diagonal lines which proves that a positive relationship exists between the pre-course and post-course tests.

From the data in Table 2, Table 3, and Table 4 above, it is evident that there is a positive correlation between the pre-course test and the post-course test. However, the relationships were stronger in earlier years and weakened during the latter years. This is not a negative attribute, however, as it shows that although a positive relationship exists, students' levels of English improved through the courses that were offered to them during the time spent in the program.

In summary, it can be deduced that the English language tests are valid and reliable as they show a positive correlation between the two tests. Moreover, the data shows that there is a trend that represents the improvement of students' performance from earlier years towards more recent years. However, what is of tremendous concern, is the fact that a large number of students do not reach the desired level of $70 \%$ or the completion of the B1 level according to the CEFR scales.

\subsection{Correlating students' English language competencies to overall academic performance}

The third part of this study correlates students' English language skills that were determined using the pre-course test with the students' overall averages in all the courses offered in the program. The data is presented below in both tabular and graphical modes. The table shows the statistical correlation co-efficient, whilst the scatter plots in the appendix show the same correlation graphically.

Table 5: Correlations between the English Language Pre-Course Test and Overall Averages

\begin{tabular}{|c|c|c|c|c|c|c|}
\hline Year & Sem & Semester & $\mathbf{N}$ & Correlation & Avg-Sem & Avg-Year \\
\hline \multirow{4}{*}{ 2014-2015 } & \multirow{2}{*}{ SEM1 } & SEM1-PLAN A & 1921 & 0.763 & \multirow{2}{*}{0.791} & \multirow{4}{*}{0.801} \\
\hline & & SEM1-PLAN B & 2122 & 0.819 & & \\
\hline & \multirow{2}{*}{ SEM 2} & SEM2-PLAN A & 1730 & 0.790 & \multirow{2}{*}{0.811} & \\
\hline & & SEM2-PLANB & 1653 & 0.831 & & \\
\hline \multirow{4}{*}{$2015-2016$} & \multirow{2}{*}{ SEM1 } & SEM1-PLAN A & 1959 & 0.766 & \multirow{2}{*}{0.803} & \multirow{4}{*}{0.831} \\
\hline & & SEM1-PLAN B & 2231 & 0.839 & & \\
\hline & \multirow{2}{*}{ SEM2 } & SEM2-PLAN A & 1829 & 0.845 & \multirow{2}{*}{0.859} & \\
\hline & & SEM2-PLANB & 1580 & 0.872 & & \\
\hline
\end{tabular}




\begin{tabular}{|c|c|c|c|c|c|c|}
\hline \multirow{4}{*}{ 2016-2017 } & \multirow{2}{*}{ SEM1 } & SEM1-PLAN A & 2235 & 0.843 & \multirow{2}{*}{0.863} & \multirow{4}{*}{0.839} \\
\hline & & SEM1-PLAN B & 2309 & 0.882 & & \\
\hline & \multirow{2}{*}{ SEM2 } & SEM2-PLAN A & 1910 & 0.796 & \multirow{2}{*}{0.816} & \\
\hline & & SEM2-PLANB & 1868 & 0.836 & & \\
\hline \multirow{4}{*}{ 2017-2018 } & \multirow{2}{*}{ SEM1 } & SEM1-PLAN A & 2322 & 0.772 & \multirow{2}{*}{0.816} & \multirow{4}{*}{0.819} \\
\hline & & SEM1-PLAN B & 2411 & 0.860 & & \\
\hline & \multirow{2}{*}{ SEM2 } & SEM2-PLAN A & 2098 & 0.816 & \multirow{2}{*}{0.823} & \\
\hline & & SEM2-PLANB & 2056 & 0.829 & & \\
\hline \multirow{4}{*}{ 2018-2019 } & \multirow{2}{*}{ SEM1 } & SEM1-PLAN A & 2822 & 0.785 & \multirow{2}{*}{0.821} & \multirow{4}{*}{0.867} \\
\hline & & SEM1-PLAN B & 2821 & 0.857 & & \\
\hline & \multirow{2}{*}{ SEM2 } & SEM2-PLAN A & 1986 & 0.842 & \multirow{2}{*}{0.912} & \\
\hline & & SEM2-PLANB & 2515 & 0.982 & & \\
\hline
\end{tabular}

From the table above, it is evident that there is a positive correlation between the pre-course English language test and the overall student averages at the end of the academic year. However, the relationships were slightly weaker in earlier years and strengthened during the latter years. This is not a negative attribute, however, as the changes are minuscule and insignificant at most. The data is also presented graphically in scatter plots (appendix 1) to provide visual representations of the power of the relationships.

By comparing the data from the pre-course test of English language skills and students' overall averages on the foundation year program, the scatter plots reveal that a positive relationship exists between the two tests. They show fairly straight diagonal lines from the bottom left to the top right which proves that a positive relationship exists between the pre-course English test and students' overall scores on the scientific courses.

Therefore, it can be deduced that the English language placement test is a fairly strong indicator of students' potential academic performance in the foundation year program. Moreover, it can be used as a predictor of students' overall performance in the foundation year program. In addition, the data suggests that whether students were in Plan A or Plan B in the first semester is insignificant as the results are fairly similar for both options.

\section{Discussion and recommendations}

The elaboration of the findings, their interpretations, implications, and recommendations in this section address four key themes. The first deals with the administration of the Q: Skills Placement Test. The second theme deals with the predictiveness of academic success through English language competencies. The third theme discusses the implications and recommendations in terms of curriculum design. The fourth theme explores the challenges faced by using a Eurocentric frame of reference in the design of Saudi Arabian curricula.

Although the placement test can is validated using the test-retest method, the results of students did not show much improvement between the two tests. This finding can be understood through an explanation of the structure of the program though. Since all students are required to take both ENG101 and ENG102, students who were already at the A2 level at the beginning of the academic year made no substantial improvement to their language level according to the CEFR scales. This implies that the structure of the program needs to be modified so that students who are at the required A2 level should be exempted from the ENG101 course and proceed directly into the ENG102 course. Also, the English pre-course test should be administered prior to students receiving their schedules. In this way, students can be streamlined into learner-centered courses. Such a diagnostic function of the test would also strengthen the purposefulness of the test, which currently only serves as a measurement of progress.

Moreover, the data evidenced in this study suggest that the English language placement test has a high degree of predictiveness. This coincides with Kamrul Hasan \& Akhand (2014) and Fakeye \& Ogunsiji's (2009) studies where they concluded that proficiency in the English language has a strong positive relationship with academic success in foreign language settings where English is used as the language of instruction. However, there are some serious implications if we are to accept the predictive nature of the English language test. This means that students who enter the program at the A1 level or obtain a score less than 30 on the English pre-course test are almost certain to fail the program. This needs to be carefully addressed from a curriculum perspective as the same group of students would also contribute to the high drop-out rate if this 
trend continues without redress. Given the predictive power of English language skills on academic success, it would be prudent to create a basic pre-A1 level course wherein students focus entirely on honing their basic English language skills without taking other courses from the foundation-year program.

Another important theme that emerges is that the program, in its current state, adopts a one-size-fits-all mentality, whereas the data shows that such an approach is ineffective for the group of students who fall in the under $30 \%$ bracket. Moreover, the data indicates that students of sub-standard English at the onset are overawed by the program which is mostly delivered in English. Therefore, a different approach is necessary. Perhaps, a starting point would be to heed to the calls of previous studies such as Alebeikan \& Troudi (2010), Alshuweikhat et al., (2016), Khan (2011), and Yusuf (2017) by developing their own standards for English in education. This will also tie in with the dictates of the country's Vision 2030 which calls for the Saudization of the various sectors of the economy for sustainability.

A significant finding that emerges through the interrogation of the data pertains to the CEFR. Although the CEFR can be used to benchmark tests and provide instruction (Author \& Sheik, 2020), the categorization of levels is in pressing need of redress. Considering the fact that students study English in the primary, intermediate, and secondary school stages, a sizeable portion of students still enter university at the A1 level. The inability of students to progress to the A2 level can be understood through a comparative linguistics approach. European languages, such as German, for instance, have similar literacy foundations that are easily transferable to the English language and allow such first language learners to enter at the current A1 level. However, Arabic has different orthographic, grammatical, lexical, and literary norms which are ignored in the current CEFR framework. Therefore, this study echoes Author and Sheik's (2020) sentiments by noting that the CEFR, in its current form is incomplete and discriminatory against Arabic speakers. A potential solution would be to include a band below the current A1 level by outlining the standards and Can-Do-Statements for early literacy.

\section{Conclusion}

This study makes three important findings that are of benefit to university level curriculum designers in Arabic-speaking countries and Saudi Arabia in particular. Firstly, there is a definite need for the foundation year program to prepare students for academic studies in the English language. Secondly, the Q: Skills English language placement test is both valid and predictive. Its predictive power can be used to identify vulnerable students and tailor the curriculum in a way in which their peculiar linguistic and literacy needs are met. This can be achieved by creating a prerequisite semester program for students who score below 30 on the placement test or are at the A1 level on the CEFR scales. However, this study also recommends that the CEFR scales be expanded to include a level as a prerequisite to the A1 level. Keeping Saudi Arabia's Vision 2030 in mind, this study also proposes that a body be established for the purpose of setting English language standards for education in Saudi Arabia so as to be self-sufficient and not dependent on external or foreign entities who might ignore local contexts and challenges. Such a team of researchers would need to collaborate with the relevant stakeholders in the Ministry of Education as well as university-level curriculum designers. This would be a watershed moment in the evolution of the English language in Saudi Arabia and would allow it to charter its own course rather than being restricted in part to that of the CEFR.

Funding: This research received no external funding.

Declaration : The authors declare no conflict of interest.

\section{References}

[1] Addow, A. M., Abubakar, A. H., and Abukar, M. S. (2013). English language proficiency and academic achievement for undergraduate students in Somalia. Educational Research International, 2(2), 59-66.

[2] Alasmari, J., Watson, J., and Atwell, E.S., (2016) A comparative analysis between Arabic and English of the verbal system using Google Translate. In: Proceedings of IMAN'2016 4th International Conference on Islamic Applications in Computer Science and Technologies. IMAN'2016 4th International Conference on Islamic Applications in Computer Science and Technologies, 20-22 Dec 2016, Khartoum, Sudan.

[3] Alebaikan, R. \& Troudi, S. (2010). Online discussion in blended courses at Saudi universities. Procedia-Social and Behavioral Sciences, 2(2), 507-514.

[4] Alfahadi, A. (2012). Saudi teachers' views on appropriate cultural models for EFL textbooks: Insights into TESOL teachers' management of global cultural flows and local realities in their teaching worlds (Unpublished doctoral dissertation). University of Exeter, Exeter, UK.

[5] Al Khairy, M.H. (2013). English as a foreign language learning demotivational factors as perceived by Saudi undergraduates. European Scientific Journal, vol 9(32). 365-382. 
[6] Alresheed, S. (2012). Exploring the nature of Saudi English teachers' beliefs and attitudes toward EFL and its effect on their teaching practice. Paper presented at The Saudi Scientific International Conference 2012. London.

[7] Alshammari, A. (2015). Developing the English curriculum in the kingdom of Saudi Arabia: possibilities and challenges. Arab World English Journal, 6(4), $365-372$.

[8] Alshuwaikhat, H. M., Adenle, Y. A., \& Saghir, B. (2016). Sustainability Assessment of Higher Education Institutions in Saudi Arabia. Sustainability, 8(8), 750. https://doi.org/10.3390/su8080750

[9] CEF. (2001). Common European Framework of Reference. Cambridge: Cambridge University Press.

[10] Cohen, L., Manion, L., and Morrison, M. (2007). Research methods in education. London: Routledge.

[11] Dev, S and Qiqieh, S. (2016). The relationship between English language proficiency, academic achievement and selfesteem of non-native-English-speaking students. International Education Studies. 9(5). 147-155.

[12] Fakeye, D.O. \& Ogunsiji, Y. (2009). English language proficiency as a predictor of academic achievement among EFL students in Nigeria. European Journal of Scientific Research, 37(3). 490-495.

[13] Kachru, B. (1985). Standards, codification, and sociolinguistic realism; The English language in the outer circle. In R. a. Quirk, English in the world: Teaching and learning the language and literatures. Cambridge: Cambridge University Press.

[14] Kachru, B. (1986a). The Alchemy of English: The Spread, Functions, and Models of Non-native Englishes. Oxford: Pergamon Press. (South Asian edition), New Delhi: Oxford University Press.

[15] Kachru, B. (1987). The power and politics of English. World Englishes, 5(2), 121-40.

[16] (Author), and Sheik, A. (2020). A critical review of the Oxford Q-skills placement test at a Saudi Arabian university. Arab Journal of Applied Linguistics. In press.

[17] Kamrul Hasan, M., and Moniruzzaman Akhand, M. (2014). EFL Students' English Language Proficiency and Academic Achievement. ABAC Journal. 32, (2) 64-70.

[18] Khajavy, G. H., Maclntyre, P., Hariri, J. (2020). A closer look at grit and language mindset as predictors of foreign language achievement. Studies in Second Language Acquisition. (In Print).

[19] Khan, I. A. (2011). An analysis of learning barriers: The Saudi Arabian context. International Education Studies, 4(1), 242247. https://doi.org/10.5539/ies.v4n1p242

[20] Leung, C., and Lewkowicz, J. (2006). Expanding horizons and unresolved conundrums: language testing and assessment. TESOL Quarterly, 40(1), 211-234.

[21] Lynch, B.K. (1997). In search of the ethical test. Language Testing, 14(3). 315-327.

[22] Mack, L. (2010). The Philosophical Underpinnings of Educational Research. Polyglossia, 19.5-11.

[23] Mahib ur Rahman, M. and AlHalsoni, E. (2013). Teaching English in Saudi Arabia: Prospects and challenges. Academic Research International, 4(1), 112-118.

[24] Siddiek, A. (2011). Standardization of the Saudi Secondary school Certificate Examinations and their anticipated impact on Foreign Language Education. International Journal of Humanities and Social Science, 1(3), 57-64.

[25] Wahyuni, D. (2012). The research design maze: Understanding paradigms, cases, methods, and methodologies. Journal of Applied Management Accounting Research, 10(1), 69-80.

[26] Yusuf, N. (2017). Changes required in Saudi universities curriculum to meet the demands of 2030 vision. International Journal of Economics and Finance, 9(9), 111-116. 


\section{Appendix}

Scatter plots showing correlations between the English pre-course test and overall averages

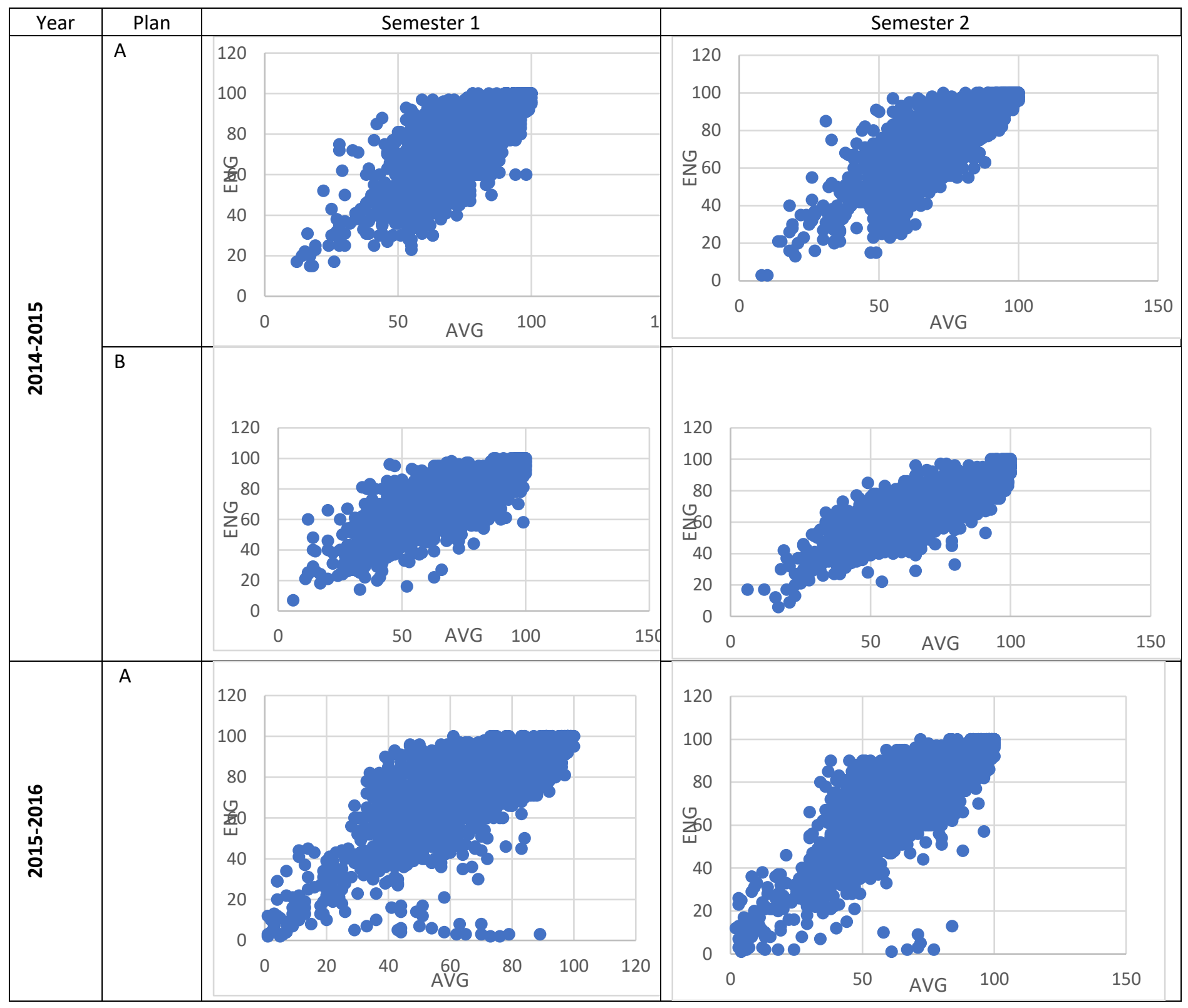




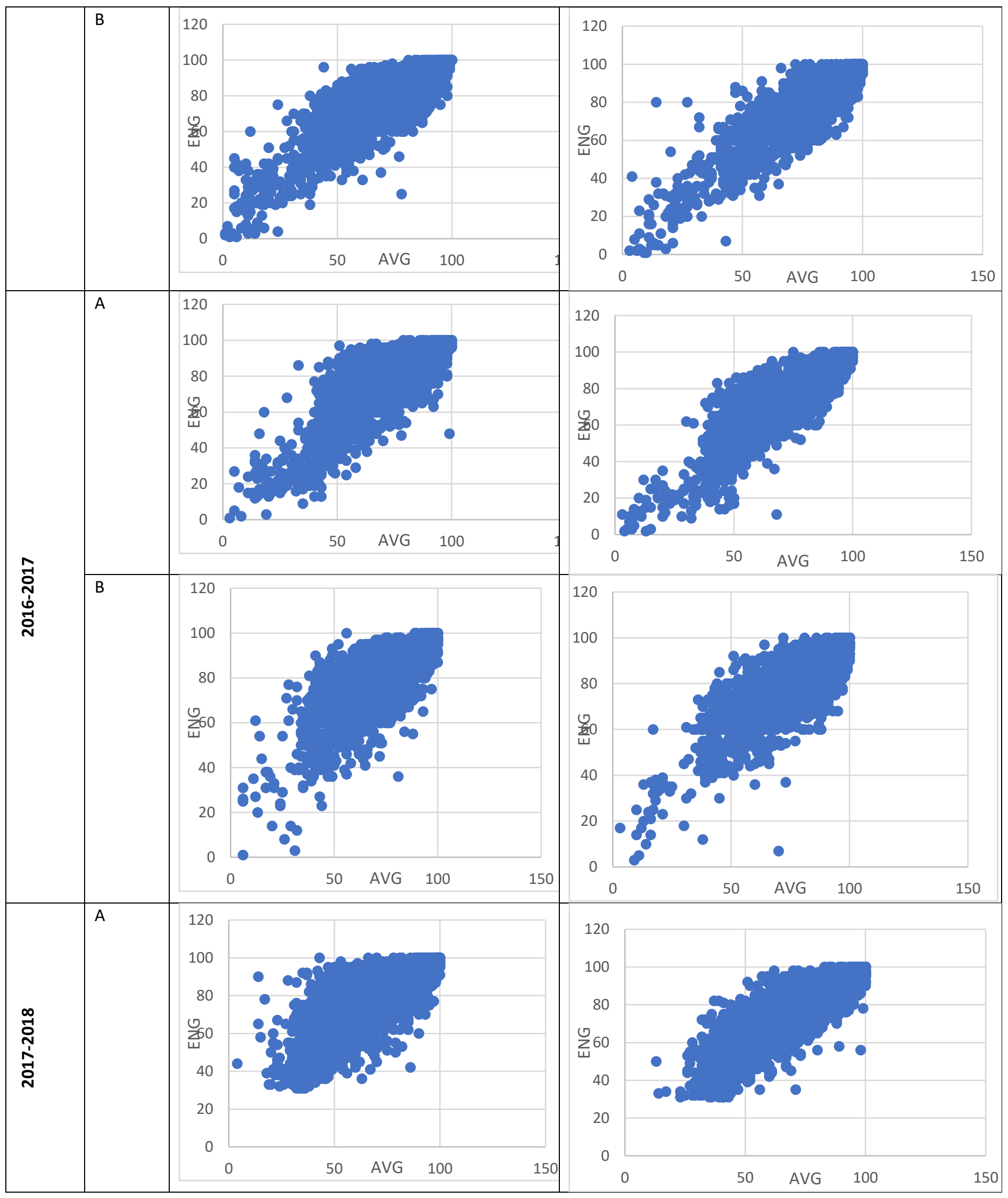




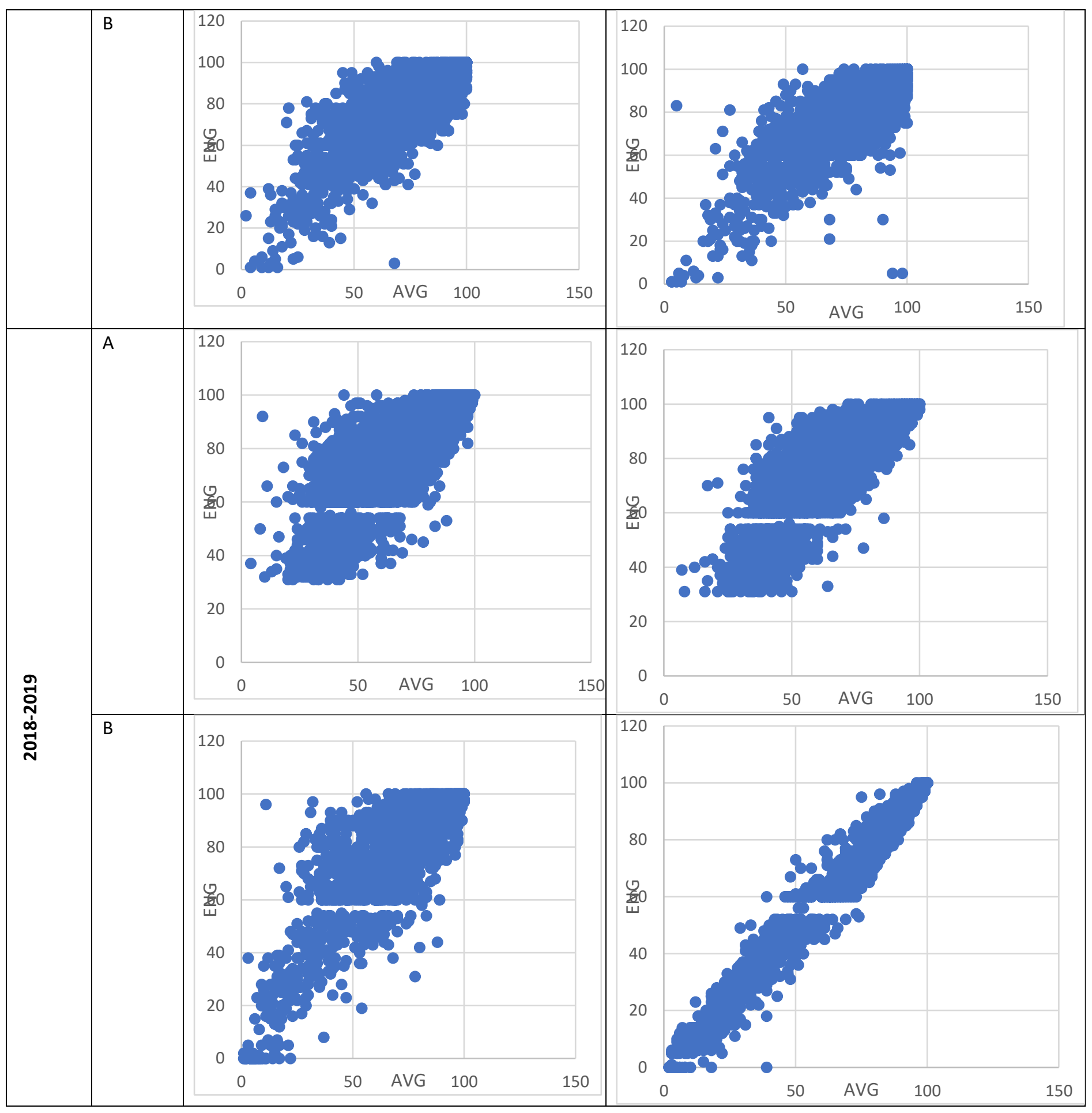

